\title{
Intra- and interspecific interactions and environmental factors determine spatial-temporal species assemblages of rodents in arid grasslands
}

\author{
Guangshun Jiang $\cdot$ Jun Liu $\cdot$ Lei Xu • \\ Chuan Yan $\cdot$ Honglin $\mathrm{He} \cdot$ Zhibin Zhang
}

Received: 10 September 2013/Accepted: 25 April 2014/Published online: 9 May 2014

(C) Springer Science+Business Media Dordrecht 2014

\begin{abstract}
Many factors have been shown to affect species assemblages of a community, but studies using long-term spatial-temporal community data are still lacking. In this study, by using population abundance data of 14 rodent species over 25 years in 21 sampling sites, we investigated the effects of taxonomic relation, density dependency, species interaction and climate variation in determining spatial-temporal species assemblages of rodents in arid grasslands of Inner Mongolia in China. By the use of GAMM analysis, we found that intraspecific interactions were more common and more significant than interspecific interactions. Negative interactions between species of the same genus were more common than negative interactions between species of different genera. Dominant species show negative interactions on less abundant or rare species. Positive interactions often occur within
\end{abstract}

Electronic supplementary material The online version of this article (doi:10.1007/s10980-014-0039-6) contains supplementary material, which is available to authorized users.

G. Jiang

College of Wildlife Resources, Northeast Forestry

University, Harbin 150040, Heilongjiang,

People's Republic of China

G. Jiang $\cdot$ L. Xu $\cdot$ C. Yan $\cdot$ Z. Zhang $(\bowtie)$

State Key Laboratory of Integrated Management of Pest Insects and Rodents in Agriculture, Institute of Zoology, Chinese Academy of Sciences, Beijing 100101,

People's Republic of China

e-mail: zhangzb@ioz.ac.cn rare or less abundant species. Through cluster analysis, we found species assemblages of rodent communities are well explained by assemblages of environmental variables, and species of same genus tend not to occur together as compared to species of the same family. Our results indicate that resource partitioning through intra- or interspecific competition and environmental filtering by climate and vegetation are important forces in shaping the spatial-temporal community structure and the dynamics of small mammal populations in an arid grassland landscape.

Keywords Species competition and coexistence $\cdot$ Density dependence .

Environmental filter - Species assemblage ·

Rodent community

\section{Introduction}

Many studies have suggested that great spatial and temporal variability of environment promote species

J. Liu

Inner Mongolia Center for Endemic Diseases Control and Research, Huhehot 010031, People's Republic of China

H. He

Information Management Group for the Synthesis Center of Chinese Ecosystem Research Network, Head Institute of Geographic Sciences and Natural Resources Research, Chinese Academy of Sciences, Beijing 100101,

People's Republic of China 
competitive coexistence (Steward and Levin 1973; Brown 1989; Shenbrot et al. 1991; León et al. 2013). Competitive coexistence of multiple species is likely a result of temporal and/or spatial variability in resource abundance, density-dependent resource consumption rate, as well as natality and mortality rates (Brown 1989; Kneitel and Chase 2004). The mechanism of such competitive coexistence driven by niche differentiation in both space and time is still widely explored in studies of community ecology (Chase and Leibold 2003).

Recently, phylogenetic or taxonomic relation has been shown to be important in the formation of community diversity (Losos 1996; McPeek and Brown 2000; Silvertown et al. 2001; Webb et al. 2002). Understanding contemporary trait differences of coexisting species within a phylogenetic or taxonomic framework certainly contributes to a broader understanding of the role of niche differentiation in structuring communities (Webb et al. 2002; Losos et al. 2003). Functional group traits of phylogenetic or taxonomic groups may lead to improved mechanistic linkages between environmental drivers and the species composition of communities (McGill et al. 2006; Litchman and Klausmeier 2008; Edwards et al. 2013). A phylogenetic or taxonomic approach to studying community structure provides a new perspective on the role of competition in the maintenance of community diversity by highlighting the similarities of co-occurring species as well as the differences (Losos 1996; McPeek and Brown 2000; Silvertown et al. 2001; Webb et al. 2002).

Natural population dynamics as parts of community are often driven by environmental stochasticity, demographic stochasticity, and density-dependent regulation (Cooper 2003; Lande et al. 2003; Wilson and Lundberg 2006). Between-species interactions relating to competition or mutualism may be important as well in affecting the community structure (Cushman and Whitham 1989; Viljugrein et al. 2005; Mutshinda et al. 2008). Density dependence has been widely detected in many species (Turchin 1990; Saitoh et al. 1997; Lima et al. 2006; Wang et al. 2009; Yan et al. 2012), but its role in maintaining species coexistence of a community has not been investigated in comparison to the role of interspecific interactions. At present, studies using long-term spatial-temporal community data are lacking, which limits our ability to understand the effects of intra- and
Fig. 1 a Cluster of sampling sites based on population abundance over 25 years in 21 sampling sites. b Cluster of sampling sites based on seasonal climate and vegetation variables over 25 years in 21 sampling sites. Group 1, 2, 3, 4 of the figures represents four groups for each of the two clusters. Sampling sites (circles) of same color belong to the same group. The background color shows the gradient of precipitation from high (green color) to low (brown color) in Inner Mongolia, China. Sampling site code number represents the county of Inner Mongolia: 1 Wulatezhongqi, 2 Wulateqianqi, 3 Manzhouli, 4 Guyangxian, 5 Etuokeqianqi, 6 Etuokeqi, 7 Xilinhaote, 8 Zhenglanqi, 9 Taipusiqi, 10 Xianghuangqi, 11 Wuningbatu, 12 Zhengxiangbaiqi, 13 Erlianhaote, 14 Suniteyouqi, 15 Abagaqi, 16 Chahaeryouyihouqi, 17 Huadexian 18 Siziwangqi, 19 Zhaluteqi 20 Keyouzhongqi, 21 Alukeerqinqi

interspecific interactions on species assemblage or community structure.

The purpose of our study is to test the relative importance of taxonomic relationship, density dependency, species interactions, vegetation and climate in structuring the species assemblage of 14 rodent species in the arid grassland of Inner Mongolia, China, by using long-term spatial-temporal data of 25 years, from 21 local sampling sites.

\section{Materials and methods}

\section{Study area}

The study was conducted in the Inner Mongolia Autonomous Region, located in northern China $\left(37^{\circ} 24^{\prime}-53^{\circ} 23^{\prime} \mathrm{N}, 97^{\circ} 12^{\prime}-126^{\circ} 04^{\prime} \mathrm{E}\right)$. The study sites have a cold and dry climate. The annual average temperature range is -5 to $9{ }^{\circ} \mathrm{C}$, with an average of $3.8{ }^{\circ} \mathrm{C}$, and the precipitation is $150-500 \mathrm{~mm}$, with an average of $326 \mathrm{~mm}$. Seasonal climate and vegetation exhibit environmental heterogeneity gradient from east to west; there is higher precipitation, more dense vegetation and lower temperatures in the eastern region than in the western region. This region is covered, from east to west, with meadow grassland, typical grassland and desert grassland. These form the major landscapes of this plateau (Ma et al. 2008) (Fig. 1). Baical needlegrass (Stipa baicalensis Boshev.), Siberian filifolium (Filifolium sibiricum (L.) Kitam.), and Aneurolepidium (Leymus chinensis chinese (Trin.) Tzrel) are the dominant plant species of the meadow grassland. Smirn needlegrass (S. grandis P.), Krylov needlegrass (S. kryovii Roshev.), Aneurolepidium, and Bunge Needlegrass ( $S$. bungeana 

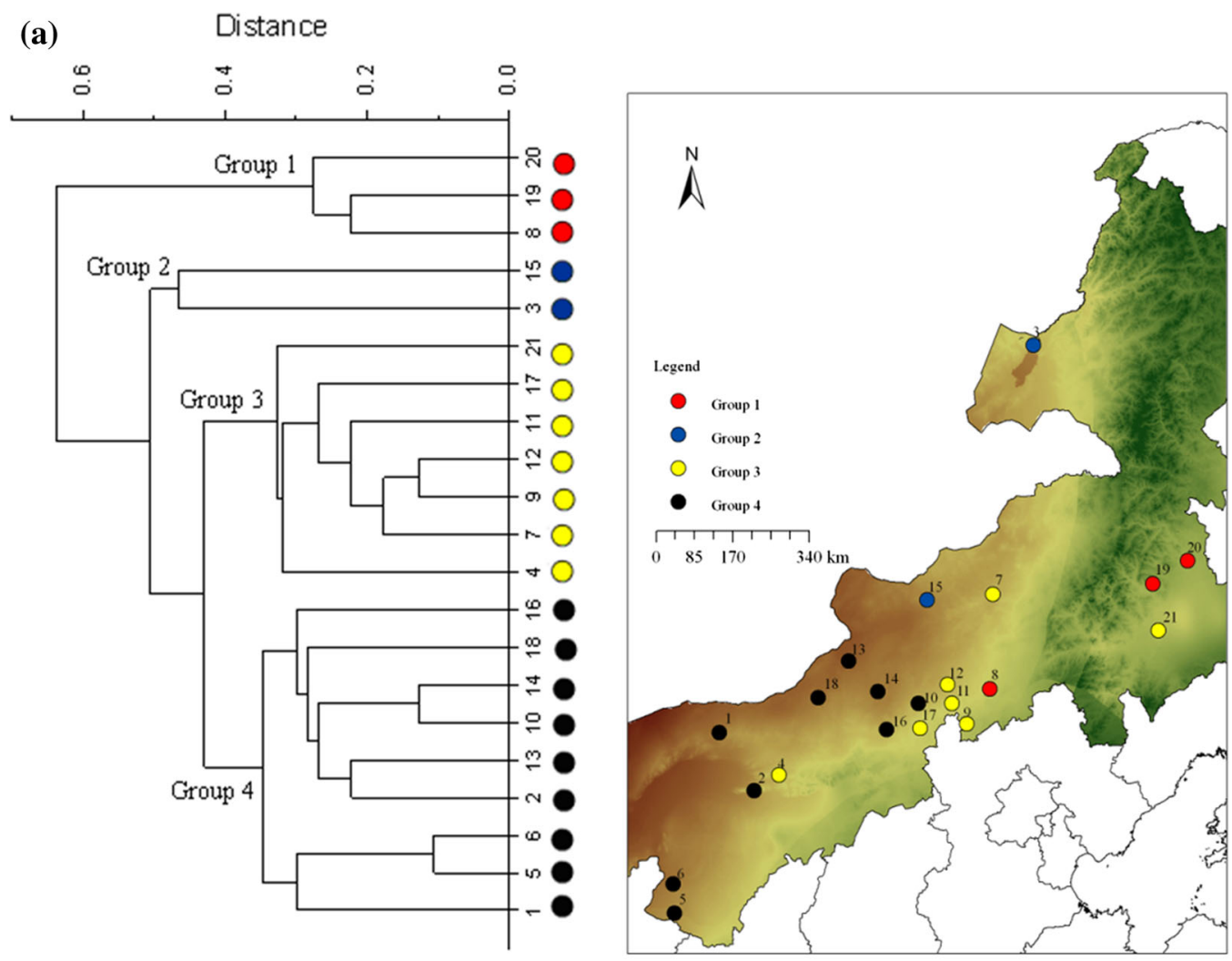

(b)

Distance
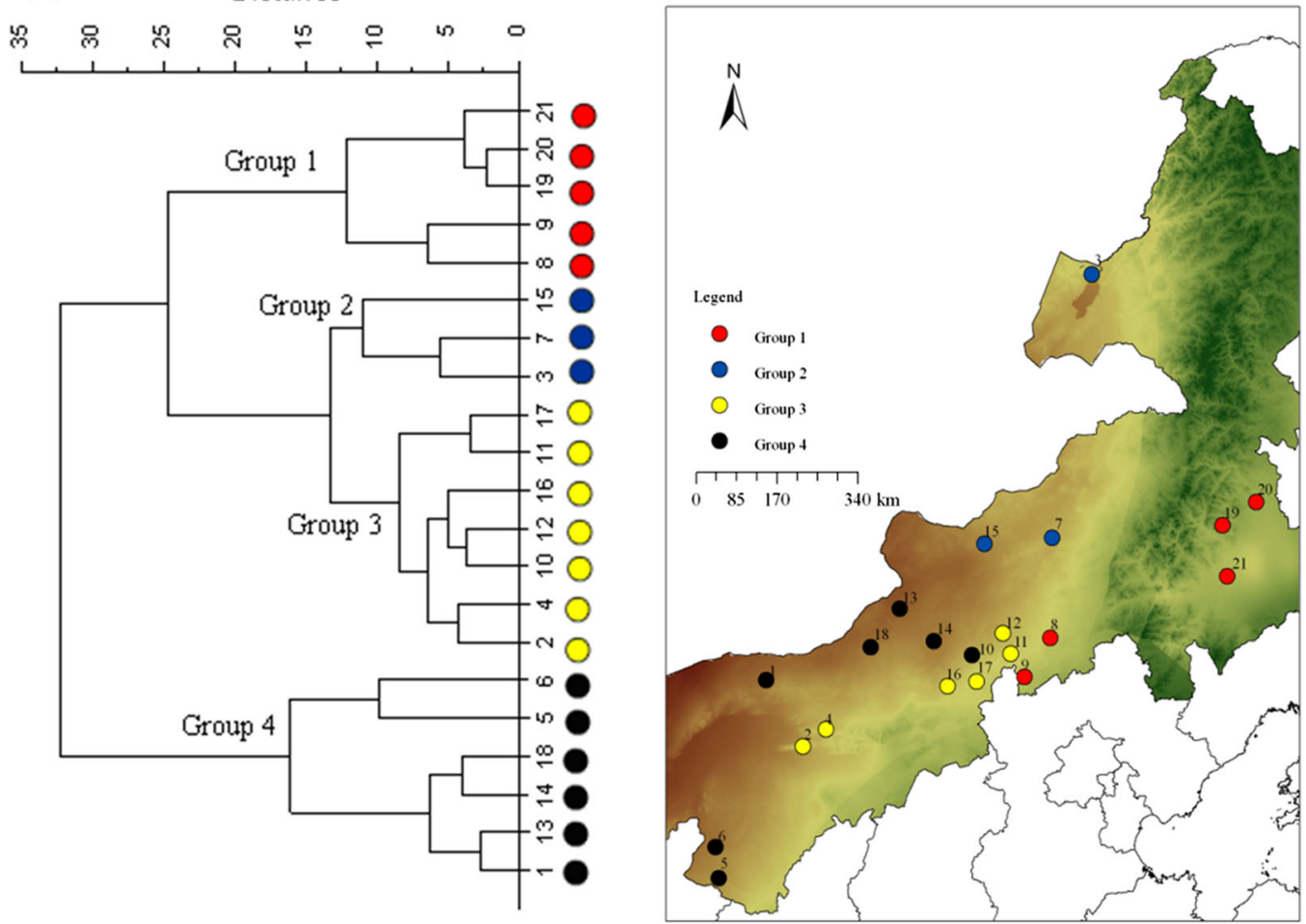
Trin) are the dominant plant species of the typical grassland. Klemenz needlegrass (S. klemenzii Roshev), Sandy needlegrass (S. glareosa P. Smirn.), and Short flower needlegrass (S. breviflora Griseb.) are the dominant plant species of the desert grassland.

Rodent abundance, climate and vegetation data

The time series dataset of rodent community obtained from the Inner Mongolia Center for endemic diseases control and research, covers 21 sampling sites (counties) and 25 years (from 1982 to 2006) in Inner Mongolia (Fig. 1). Sampling methods were consistent over time. The survey was conducted over an area of approximately 25 ha representing the predominant habitat or vegetation type of each county. From the middle of April to the middle of May and from the middle of September to the middle of October every year, 1-3 sampling plots were selected in each of the 21 sampling sites in which to capture rodents. At each plot, 100 snap-traps were baited with one flour pancake, mixed with bean oil and weighing about $2 \mathrm{~g}$, were spaced at an interval of $5 \mathrm{~m}$ along a transect line. The transect line was about $200 \mathrm{~m}$ apart. Traps were set after sunset and collected in the morning for two successive days at each plot. The captured animals were identified, weighted and dissected to check for pathogens. Only the pooled spring and autumn data which represent the annual rodent abundance were available for conducting analysis. The rodent abundance (i.e., trap success \%) is defined as: total captured animals/total snap-traps $\times 100 \%$. A total of 14 species with $>5$ years abundance data were selected for statistical analysis. The population time series of nine species (i.e., Meriones meridianus, Allactaga sibirica, Cricetulus barabensis, Phodopus roborovskii, Dipus sagitta, Meriones unguiculatus, Phodopus sungorus, Cricetulus eversmanni and Mus musculus) with more than successive 5 years are used for constructing population models (these species are defined as abundant species). The presence and absence data of 5 species (i.e., Lasiopodomys brandtii, Stylodipus telum, Spermophilus dauricus, Cricetulus migratorius and Cardiocranius paradoxus) with the proportion of presence more than 6 years and mean annual abundance $<0.1 \%$, are also used for constructing population models (these species are defined as rare species).

We obtained the monthly normalized difference vegetation index (NDVI) for the period of 1980-2006 with a resolution of $8 \times 8 \mathrm{~km}$ from the Environmental and Ecological Science Data Center for West China (EESDCWC) (website: http://westdc.westgis.ac.cn). We obtained the monthly temperature and precipitation data during 1980-2006 with a resolution of $10 \times 10 \mathrm{~km}$ from the website (http://www.cerndata. ac.cn.) We calculated the seasonal NDVI, temperature and precipitation of each sampling site based on the monthly data by using the spatial analysis tool (Zonal statistics) in ArcGIS. For detailed information as to abundance and vegetation index data, please see Jiang et al. (2011). The seasons in this study are defined as: Spring, from March to May; Summer, from June to August; Autumn, from September to November; Winter, from last December to February of this year.

Statistical analysis

\section{Cluster analysis}

We used the hierarchical cluster analysis to identify clusters of 21 sampling sites based on species abundance and seasonal climate variables (temperature, precipitation and NDVI) from 1982 to 2006 by using the Ward minimum variance method (i.e., Ward's Method) (Ward 1963). This method uses Euclidian distances as measures of similarity and produces clusters according to a criterion which minimizes variance within clusters. Then, we compared the overlap of sampling sites between two clusters to detect the effects of environmental factors in determining species assemblages of rodents. We defined the species with the highest proportion of the total community abundance as the most dominant species in each sampling site. Overlap (\%) of sampling sites is defined as the percentage of the number of same sites shared by two clusters in the total number of sampling sites of the two clusters. Overlap percentage (\%) of the most dominant species is defined as the percentage of the total number of same most dominant species shared by the two clusters in the total number of the most dominant species of two clusters.

We plotted the taxonomic cluster of the 14 rodent species by referring to Wilson and Reeder (2005) and used the Hierarchical Cluster Analysis to identify clusters of 21 sampling sites based on species abundance from 1982 to 2006 . Then we compared overlap of sampling sites between the two clusters to detect the effects of taxonomic relation on the species assemblages of rodents. 
Correlation analysis

We used the Spearman rank correlation analysis to calculate the correlation coefficients of population abundance from 1982 to 2006 between species of the same genus, and between species of the same family. Then, we calculated the mean Spearman correlation coefficients between species by using bootstrap confidence intervals (CI) based on 10,000 replications by following Efron and Tibshirani (1993). If the mean correlation coefficient is significantly larger or smaller than zero, then positive or negative correlation between species occurrences can be confirmed.

\section{GAMM analysis}

We used the generalized additive mixed models (GAMM) (Chen 2000; Ramsey and Schafer 2002; Crawley 2007) to detect the effects of intrinsic and extrinsic factors in determining population dynamics of rodents by removing potential spatial pseudoreplication caused by sampling sites. In presenting the species interactions and effects of climatic factors, we ranked species based on the mean population abundance of 14 rodent species covering 21 sampling sites over 25 years from high to low.

We used the $R$-function (see Berryman and Turchin 2001), $R_{\mathrm{t}}=\operatorname{In}\left(N_{\mathrm{t}}\right)-\operatorname{In}\left(N_{\mathrm{t}-1}\right)$, to represent the realized per-capita population change rate of the nine abundant rodent species with enough abundance data. We used per-capita population change rates ( $R$ values) as dependent variables, natural logarithm (ln) transformed population density $(X)$, ln-transformed annual population density of the other eight rodent species as competitors (denoted as $Z$ ), seasonal temperature, seasonal precipitation and seasonal vegetation (NDVI) as independent variables, and sampling sites as random factor. For the five rare rodent species with enough presence or absence data, we used the binary data (1, presence; 0 , absence) to represent their population abundances. The effects of the five rare species on the nine abundant species are ignored, but the effects of the nine abundant species on the five rare species are considered in constructing models.

Smoothed functions $\left(f_{\mathrm{i}}, h_{\mathrm{i}}\right.$ and $\left.g_{\mathrm{i}}\right)$ were all implemented by using natural cubic spline functions, with a maximum of 4 knots. A natural cubic spline is constructed from sections of a cubic polynomial, which is widely used to detect nonlinearity (Wood
2006). We defined the parameter(s) $\alpha$ as an intercept, and $\varepsilon$ as a normally distributed stochastic perturbation. The models are presented as follows:

$$
\begin{aligned}
R_{\mathrm{t}}= & \alpha_{\mathrm{t}}+f_{1}\left(X_{\mathrm{t}-1}\right)+f_{2}\left(Z_{\mathrm{t}-1}\right)+h_{1}\left(\text { temperature }_{\mathrm{t}}\right) \\
& +h_{2}\left(\text { precipitation }_{\mathrm{t}}\right)+h_{3}\left(\text { vegetation }_{\mathrm{t}}\right)+\varepsilon_{\mathrm{t}}
\end{aligned}
$$

The subscript $\mathrm{t}$ refers to annual time scale. $X_{\mathrm{t}-1}$ and $Z_{\mathrm{t}-1}$ are naturally log-transformed annual density of each rodent species in community and its all competitors in year $t-1$, respectively. Temperature ${ }_{\mathrm{t}}$ is the seasonal temperature in year $t$, precipitation ${ }_{\mathrm{t}}$ is the seasonal precipitation in year $t$ and vegetation ${ }_{\mathrm{t}}$ is the seasonal vegetation (i.e., NDVI) in year $t$. We defined the positive or negative effect of an independent factor on $R$-function if the curve shows monotonic increase or decrease. If the curve shows a non-monotonic trend, then we defined it as a non-monotonic effect. For detailed figures as to the effects of density dependency, species interaction and environmental factors on $R$-function of rodent species, please see the Supplementary Materials (Figs. S1-S13).

All analyses were carried out in $\mathrm{R}$ version 2.12.1 using the mgcv and lme4 packages (R Development Core Team 2013). The optimal roughness of the smoothing terms was determined by minimizing the generalized cross-validation value (GCV) (Stige et al. 2006). The GCV of a model is an index for the model's out-of-sample predictive mean squared error (Cox et al. 1981) and is also used to compare alternative model formulations. The best-fitting models were selected from candidate models by following the rule of minimization of GCV on the condition that all variables must be statistically significant $(P<0.05)$. We found no spatial autocorrelation among mean value of time series model residuals of each site of 21 sampling sites for each species of 14 species by using Spatial Analysis in Macroecology (SAM) software based on check of the significance of Moran's I values (Rangel et al. 2010).

Chi square analysis

Chi square or Fisher exact analysis is used to compare the significant differences in frequencies between intraspecific and interspecific interactions, or interactions between species within the same genus and nonsame genus. We used the nonparametric test and Crosstabs to conduct the Chi square test or Fisher exact analysis in SPSS 13.0 (Incorporation 2006). 
Table 1 Comparisons of sampling sites, environmental variables and most dominant rodent species of four groups between rodent and environment clusters

\begin{tabular}{|c|c|c|c|c|c|c|c|c|}
\hline \multirow[t]{2}{*}{ Group } & \multicolumn{3}{|c|}{ Sampling site codes } & \multicolumn{2}{|c|}{ Environmental characteristics } & \multicolumn{3}{|c|}{ Most dominant species } \\
\hline & $\begin{array}{l}\text { Rodent } \\
\text { cluster }\end{array}$ & $\begin{array}{l}\text { Environmental } \\
\text { cluster }\end{array}$ & $\begin{array}{l}\text { Overlap } \\
(\%)\end{array}$ & $\begin{array}{l}\text { Rodent } \\
\text { cluster }\end{array}$ & $\begin{array}{l}\text { Environmental } \\
\text { cluster }\end{array}$ & $\begin{array}{l}\text { Rodent } \\
\text { cluster }\end{array}$ & $\begin{array}{l}\text { Environmental } \\
\text { cluster }\end{array}$ & $\begin{array}{l}\text { Overlap } \\
(\%)\end{array}$ \\
\hline 1 & $8,19,20$ & $\mathbf{8 , 9 , 1 9 , 2 0 , 2 1}$ & 60 & $\begin{array}{l}\text { T: } 4.8896(2.415) \\
\text { P: } 31.114(1.203) \\
\text { N: } 0.255(0.018)\end{array}$ & $\begin{array}{l}\text { T: } 5.003(2.227) \\
\text { P: } 31.059(0.968) \\
\text { N: } 0.259(0.014)\end{array}$ & $3,3,3$ & $3,3,3,3,3$ & 100 \\
\hline 2 & 3,15 & $3,7,15$ & 66 & $\begin{array}{l}\text { T: } 0.986(1.249) \\
\text { P: } 20.728(1.872) \\
\text { N: } 0.218(0.031)\end{array}$ & $\begin{array}{l}\text { T: } 1.481(1.231) \\
\text { P: } 21.405(1.768) \\
\text { N: } 0.208(0.027)\end{array}$ & 10,2 & $10,3,2$ & 66 \\
\hline 3 & $21, \mathbf{1 7 , 1 1 , 1 2}$ & $\begin{array}{l}2,4,10, \mathbf{1 2}, 16 \\
\mathbf{1 1 , 1 7}\end{array}$ & 37 & $\begin{array}{l}\text { T: } 4.498(1.839) \\
\text { P: } 27.034(2.783) \\
\text { N: } 0.227(0.040)\end{array}$ & $\begin{array}{l}\text { T:4.303 (0.964) } \\
\text { P: } 25.489(1.691) \\
\text { N: } 0.200(0.028)\end{array}$ & $3,4,3,3$ & $2,3,2,3,2,3,4$ & 66 \\
\hline 4 & $\begin{array}{l}16, \mathbf{1 8}, \mathbf{1 4}, 10 \\
\mathbf{1 3}, 2, \mathbf{6 , 5}, \mathbf{1}\end{array}$ & $1,13,14,18,5,6$ & 66 & $\begin{array}{l}\text { T: } 5.719(1.569) \\
\text { P: } 19.242(4.837) \\
\text { N: } 0.153(0.038)\end{array}$ & $\begin{array}{l}\text { T: } 6.118 \text { (1.758) } \\
\text { P: } 18.533(4.413) \\
\text { N: } 0.142(0.029)\end{array}$ & $\begin{array}{l}2,2,2,2, \\
2,2,1,1,2\end{array}$ & $2,2,2,2,1,1$ & 100 \\
\hline
\end{tabular}

Species codes: 1, Meriones meridianus; 2, Dipus sagitta; 3, Allactaga sibirica; 4, Phodopus roborovskii; 5, Phodopus sungorus; 6 , Cricetulus eversmanni; 7, Cricetulus barabensis; 8, Meriones unguiculatus; 9, Mus musculus; 10, Lasiopodomys brandtii; 11, Stylodipus telum; 12, Spermophilus dauricus; 13, Cricetulus migratorius; 14 , Cardiocranius paradoxus

$T$ mean seasonal temperature (SD), $P$ mean seasonal precipitation (SD), $N$ mean seasonal NDVI (SD)

Sampling site codes are the same to Fig. 1

Bold sampling site codes are the overlapped ones between rodent and environmental clusters

\section{Results}

Effects of climate and vegetation

As shown in Table 1 and Fig. 1, clusters of 21 sampling sites based on rodent abundance (defined as "rodent cluster") and environmental factors (defined as "environment cluster") have a good match. Both the rodent and environment clusters show four obvious groups. There is over $60 \%$ overlap of sampling sites between the two clusters for Group 1, 2, 4 respectively, but for Group 3 there is only $37 \%$ overlap. These results indicate that community and structure and dynamics of rodents can be explained over $37-60 \%$ species assemblages by the environment factor assemblages.

The most dominant species shows $100 \%$ overlap in sampling sites between two clusters for Group 1 and 4 , $66 \%$ overlap for Group 2 and 3. Group 1 includes sites with the most dominant species Allactaga sibirica, Group 2 includes sites with the most dominant species Lasiopodomys brandtii, Dipus sagitta and Allactaga sibirica, Group 3 includes sites with the most dominant species Allactaga sibirica and Phodopus roborovskii. Group 4 includes sites with the most dominant species Meriones meridianus and Dipus sagitta. The environmental conditions between two clusters for the same group are also similar (Table 1; Fig. 1). Group 1 includes sites with high precipitation, high vegetation (NDVI) and high temperature, and they are located mainly in eastern Inner Mongolia. Group 2 includes sites of low temperature, and they are located mainly in northern Inner Mongolia. Group 3 includes sites of high temperature, and they are located mainly in central Inner Mongolia. Group 4 includes sites of high temperature and low NDVI, and they are located mainly in western Inner Mongolia (Fig. 1).

GAMM analysis (Figs. 4 and 5) indicates that eleven climate and vegetation variables show positive effects on population abundance of rodents and thirteen variables show negative effects. Spring precipitation and winter temperature shows positive effects on five of the nine abundant species. Two climate and vegetation variables show positive effects on two of the five rare rodent species; five climate and 


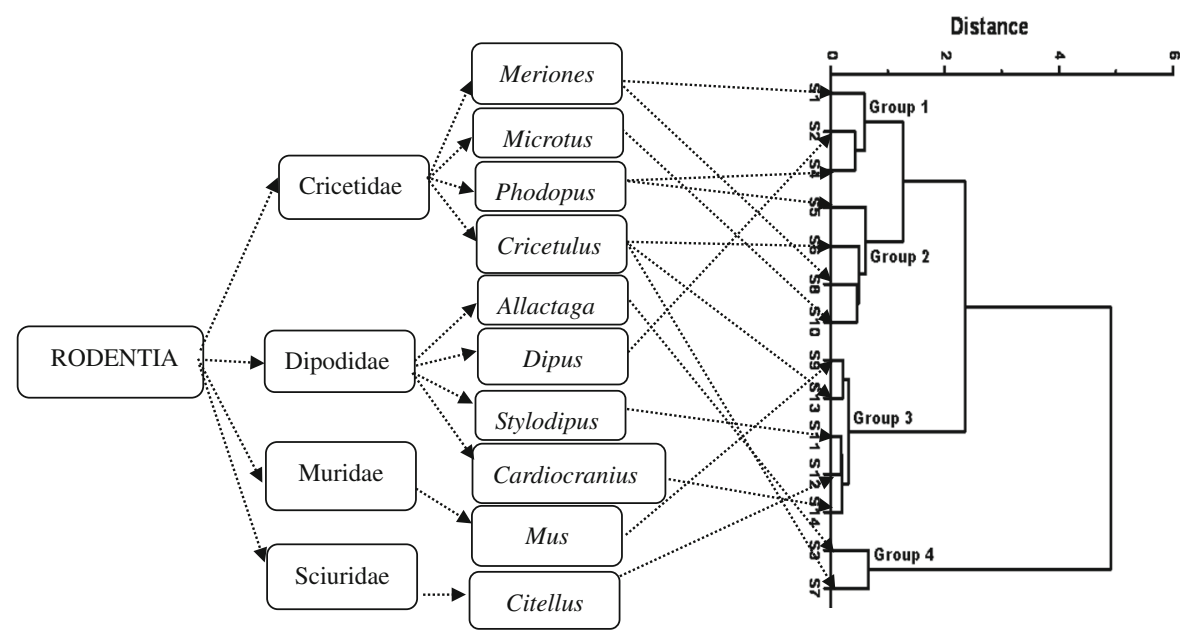

Fig. 2 Relationships between the taxonomic cluster and the species cluster for the 14 rodent species. Left taxonomic cluster. Right: species cluster based on rodent abundance over 25 years in 21 sampling sites. Species codes are defined as: S1 Meriones meridianus, S2 Dipus sagitta, S3 Allactaga sibirica, S4 Phodopus roborovskii, S5 Phodopus sungorus, S6 Cricetulus

vegetation variables show negative effects on three rodent species (Fig. 5). These results indicate that climate and vegetation factors significantly affect community dynamics of rodents; different species have similar or different responses to the climate variations.

\section{Effects of taxonomic relation}

Figure 2 shows that there are four families and ten genera for the 14 rodent species based on the taxonomic cluster (i.e., left part of Fig. 2). The 14 rodent species are clustered into four groups (Group 1, 2, 3 and 4; right part of Fig. 2) based on their abundances over 25 years in 21 sampling sites (here defined as the species cluster). No species of same genus in the taxonomic cluster is found together in the same group of the species cluster. Two of three species of the same family are found in Group 1 of the species cluster. All four species of the same family (i.e., Phodopus sungorus, Cricetulus eversmanni, Meriones unguiculatus and Lasiopodomys brandtii) are found in Group 2. Two of five species of the same family (i.e., Stylodipus telum and Cardiocranius paradoxus) are found in Group 3. Two species of different family are found in Group 4. Cricetidae has eight species, four species are found in Group 2. Dipodidae has four eversmanni, S7 Cricetulus barabensis, S8 Meriones unguiculatus, S9 Mus musculus, S10 Lasiopodomys brandtii, S11 Stylodipus telum, S12 Spermophilus dauricus, S13 Cricetulus migratorius, S14 Cardiocranius paradoxus. Arrow denotes the position of a species of the taxonomic cluster in the group of the species cluster

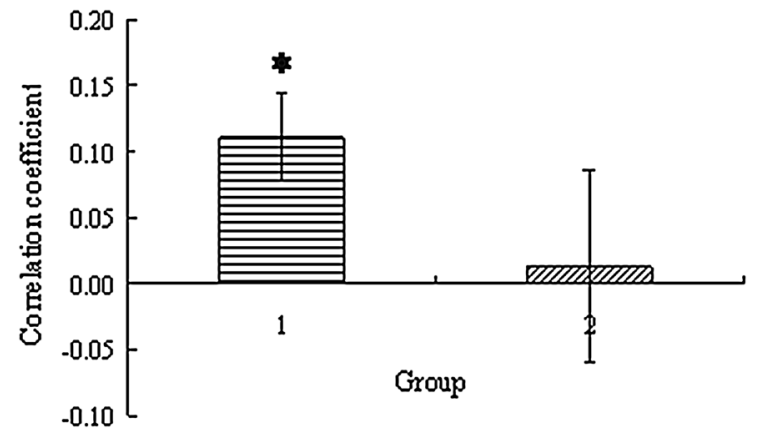

Fig. 3 Differences in mean correlation coefficients with $95 \%$ CI between species for the rodent abundances over 25 years in 21 sampling sites. Group 1 with the same family $(n=272)$. Group 2 within the same genus $(n=55)$. Asterisk denotes the mean difference is significant at the 0.05 level

species, two species are found in Group 3. Among seven species within three same genus groups, no species occur in the same group of the species cluster. Among 12 species of two same families, six species occur in the same groups (Group 1 and 3). More species of Cricetidae are found in Group 1 and 2, while four species of the Family Dipodidae are less well grouped. Figure 3 indicates that species of same genus has no significant correlation in population abundances, but species of same family show significant and positive associations. These results suggest that 

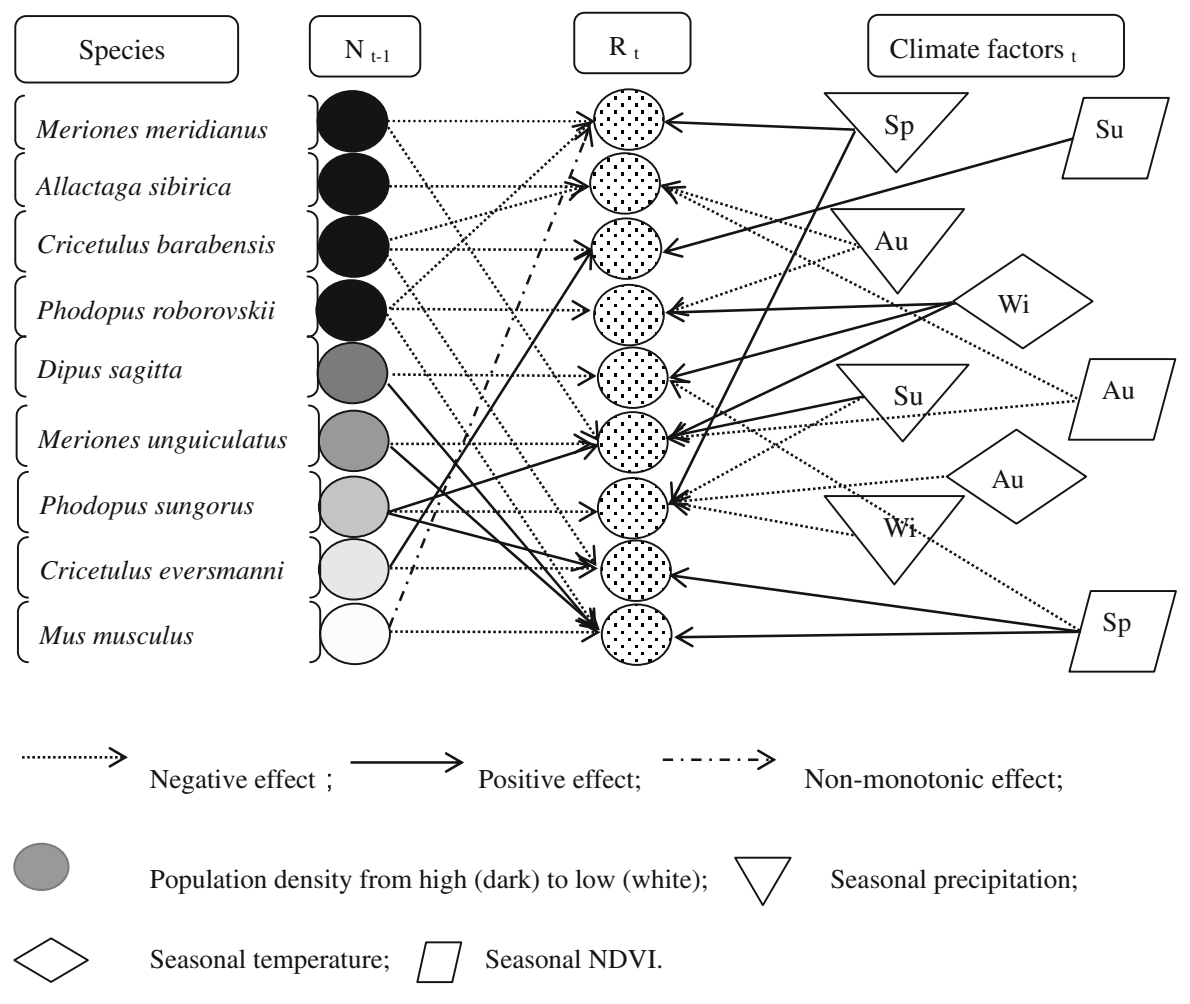

Fig. 4 Effects of density dependency, species interaction and environmental factors on $R$-function of nine abundant rodent species identified by using GAMM. $N_{\mathrm{t}-1}$, population density of rodents at the previous year; $R_{\mathrm{t}}$, yearly per-capita population

closely-related species do not occur together as compared to species of the same family.

\section{Effects of interspecific interaction}

Figures 4 and 5 show that 18 significant interspecific interactions were detected, including seven positive interactions, seven negative interactions and four nonmonotonic interactions for the 14 species. In theory, there could be 14 species $\times 13$ interactions of each species $=182$ interspecific interactions among 14 species. As shown in Fig. 2, in theory, there are ten possible species interactions occurring with the same genus (teo interactions for two species of Meriones, two interactions for two species of Phodopus, six interactions for three species of Crecetulus) and 172 species interactions (i.e., $182-10=172$ ) between species of the non-same genus. Of the seven negative interactions observed in Figs. 4 and 5, two are within same genus (with the probability $=2 / 10=20 \%$ ), five are within change rates at year $t . S p$ spring, $S u$ summer, $A u$ Autumn and $W i$ winter. The grayness of the circle indicates the population abundance from high (dark) to low (white). See the GAM response curve maps in Part 1 of the supplementary materials

the non-same genus (with the probability = $5 / 172=2.9 \%)$. The probability of negative interaction (competition) between species of the same genus is significantly higher than that of species not within the same genus (Fisher's Exact Test $P=0.049$ ).

Figure 4 shows less abundant species suffer negative interactions (competition) from high-abundant species $\quad(M . m \rightarrow M . u, \quad C . b \rightarrow$ C.e $; \quad$ P.r $\rightarrow$ M.m). Abundant species also suffer competition from high abundant species $(C . b \rightarrow A . s, P . r \rightarrow M . m)$. No high abundant species suffer competition from less abundant species. Positive interactions occur within less abundant species $\quad(D . s \rightarrow M . m ; \quad M . u \rightarrow M . m$; $P . s \rightarrow$ C.e) or from less abundant species to abundant species $(C . e \rightarrow C . b)$. Fig. 5 indicates that rare species suffer competition from abundant species $(C . b \rightarrow L . b$; $P . r \rightarrow L . b)$; positive density dependency effect is found for two rare species ( $L . b$ and C.p). Two positive interactions are found from less abundant to rare species $(M . m \rightarrow$ S.t, M.u $\rightarrow$ S.d). 


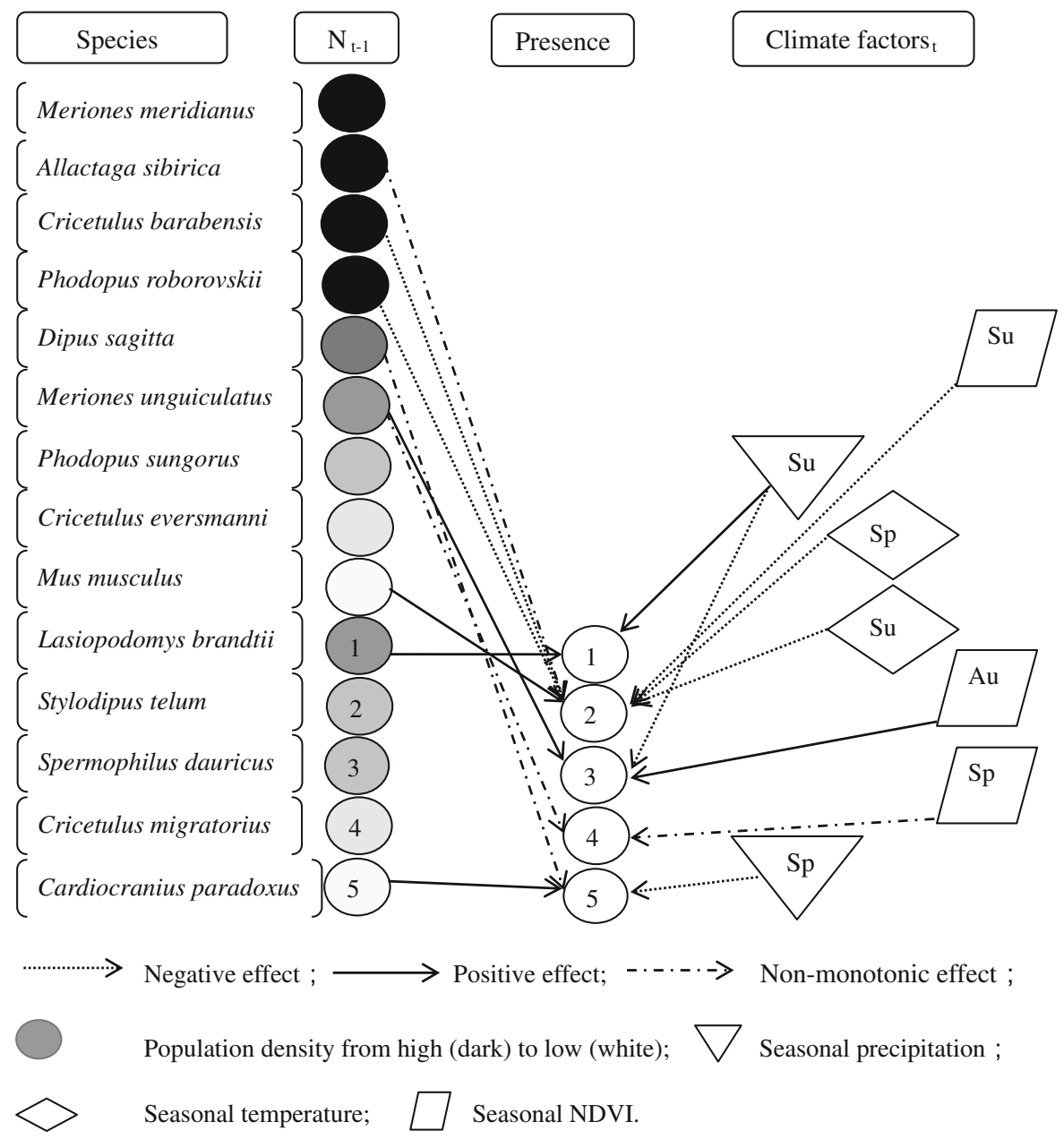

Fig. 5 Effects of density dependency, species interaction and environmental factors on $R$-function of five rare rodent species identified by using GAMM. $N_{\mathrm{t}-1}$, population density (or presence/absence) of rodent in the previous year; $N_{\mathrm{t}}$, presence (1) or absence (0) of rodents at year $t . S p$ spring, $S u$ summer, $A u$

Effects of density dependency (intraspecific interaction)

Figures 4 and 5 indicate that 11 species (nine abundant species and two rare species) exhibit density dependency effect (the probability of intraspecific interaction $=11 / 14=78.6 \%$ ). There are 18 interspecific interactions with a probability of $18 / 182=9.9 \%$ which is significantly smaller than that of the intraspecific interactions $\left(\chi^{2}=98.07, \mathrm{df}=1, P<0.001\right)$. Figure 4 shows all the 9 abundant species have negative density dependency effect but with no positive density dependency effect. Figure 5 shows that positive density dependence effect occurs in two
Autumn and $W i$ winter. 1, 2, 3, 4, 5 indicates the rare species code, respectively. The grayness of the circle indicates the population abundance from high (dark) to low (white). See the GAM response curve maps in Part 2 of the supplementary materials

rare species (Lasiopodomys brandtii and Cardiocranius paradoxus); no negative density dependence effect is found in the 5 rare species. These results indicate that density dependency also contributes to observed spatial-temporal species assemblages, and intraspecific interactions are more prevalent than interspecific interactions in the rodent community.

\section{Discussion}

By using long-term spatial-temporal data of rodent community data, we found species assembly of small rodents was closely associated with both intrinsic and 
external factors of rodent communities. Intraspecific (or closely-related species) show more competition, probably due to high competition under similar niche requirements or overlaps. Vegetation and climate variables showed different effects on different species, but species assembly was very positively associated with environmental combinations, suggesting environmental filter played a significant role in structuring spatial-temporal species assembly and abundances.

\section{Effects of environmental factors}

The role of environmental variables in determining community structure and dynamics has long been noted as predicted by the niche theory (Hutchinson 1957, 1959). Kotler and Brown (1988) suggested that environmental heterogeneity such as spatial and temporal variability in resource productivity and availability, predatory risk, and seasonal climatic factors may potentially allow species coexistence. For example, in their research on water ecosystems, Clarke and Ainsworth (1993) found macrobenthic, meiobenthic and diatom community structures had a good match with abiotic variables based on analysis of similarity matrices between them in estuarine and coastal waters. Austin (1985) demonstrated that species composition along environmental gradients was closely linked to changes in vegetation as a continuum due to spatial niche partitioning. Brown (1989) showed that different environmental conditions resulted in different species compositions in the rodent community. Our results suggest that there is a 37-60 \% match in sampling sites between a rodent cluster and an environmental cluster, suggesting that spatial-temporal heterogeneity in environments is important in affecting species composition and dynamics. Additionally, our GAMM analysis reveals that precipitation, temperature and vegetation (NDVI) show significant effects on the population dynamics of rodent species. Previous studies also indicate that different species or groups have different responses to climatic variations (Jiang et al. 2011; Zhang 2013), showing a trade-off in life history while responding to environmental variables.

The environment of the Inner Mongolia plateau shows a strong gradient from south to north and from east to west (Fig. 1). Wetter in the east than in the west, and colder in the north than in the south, which results in four main environmental groups and so also four rodent species assemblages. Allactaga sibirica is widely distributed in northeastern and central Inner Mongolia. Lasiopodomys brandtii is dominant in northern Inner Mongolia. Dipus sagitta is dominant in northwestern Inner Mongolia. Phodopus roborovskii is dominant in central Inner Mongolia. Meriones meridianus is dominant in the desert habitats of western Inner Mongolia. It is notable that there is still a large proportion of non-overlap of sampling sites between rodent and environmental clusters. Sampling errors or stochastic factors or species interaction may also contribute to the observed community patterns and dynamics.

\section{Effects of taxonomic relation}

Darwin (1859) was first to proposed that species in the same genus would be more likely to compete than those in different genera. Thus, taxonomic relation may be important in shaping community structure and dynamics (McPeek and Brown 2000; Webb et al. 2002; Silvertown et al. 2001). Webb and Peart (2000) found species of both genera and families of rain forest trees are closely associated with particular habitat types. Cooper et al. (2008) found that mammal assemblages displayed a highly significant tendency for species to be more distantly-related than expected by chance; close relatives showed evidence of competition, while distant relatives showed evidence of convergent evolution. However, Winston (1995) found no difference in co-occurrence frequencies between groups of closely-related and distantlyrelated stream fishes, but co-occurrence was less among morphologically similar species than among less similar ones. It is believed that closely-related species tend to occur together on a large scale driven by environmental filtering, but they do not occur in a microhabitat scale driven by the competition exclusion principle (Keddy and Weiher 1999; CavenderBares et al. 2006). Our results also indicate that closely-related species tend not to occur together in both space and time patterns (Figs. 2 and 3), probably due to high competition among relatives as suggested by Darwin (1859) (also see below). Our study suggests that the competition exclusion principle may more work according to a spatial-temporal scale in which niche overlap between species would be larger than that on a large spatial scale. 
Effects of inter- and intraspecific interaction

Closely-related species may have strong competition because they share a similar ecological niche (Darwin 1859; Cross and Benke 2002). Dominant species may be important in regulating community stability (Sasaki and Lauenroth 2011). Cross and Benke (2002) suggested that competition between closely-related coexisting lotic snails may be more important, because strong interspecific competition occurs among Elimia cahawbensis and Elimia carinifera, which together comprise $75 \%$ of the entire invertebrate biomass at Hendrick Mill Branch. Unfortunately, quantitative studies on interspecific competition between closelyrelated groups or distantly-related groups are rare. By using long-term spatial-temporal data, our results provided clear evidence that the frequency of interspecific competition between species of the same genus of rodents is significantly greater than that between species of rodents in different genera. This explains why species of the same genus do not tend to occur together. Even more interesting is that we found species competition determined the ranks of abundance in rodent communities less abundant or rare species often faced competition from abundant species. Therefore, taxonomically-related species competition is a very important force in determining species assemblages. In addition, we found five positive species interactions between less abundant species (D.s $\rightarrow$ M.m; M.u $\rightarrow$ M.m;P.s $\rightarrow$ C.e $)$ or from less abundant species to abundant species $(C . e \rightarrow C . b)$ (Fig. 4) and 2 positive species interactions from less abundant to rare species $(M . m \rightarrow$ S.t, $M . u \rightarrow S . d$ ) (Fig. 5). The mechanism of these positive interactions between rodent species is not clear. They are perhaps the result of indirect effects caused by climatic variations or predation. Within the study region, a previous study indicates that climate warming benefits the population growth of many rodent species (Jiang et al. 2011), and especially favors rare species (Jiang et al. 2013). Travis et al. (2006) suggested that positive interactions may be found where there is high abiotic stress. There is a need to explore the underlying mechanisms of the observed positive interactions.

Though density dependency (intraspecific competition) or interspecific competition is commonly seen in single population dynamics (Saitoh et al. 1997; Lima et al. 2006; Turchin 1990; Wang et al. 2009; Yan et al. 2012), it is still not clear how it affects species coexistence and community structure. Classic LotkaVolterra competition theory predicts that stable coexistence should occur only if the effects of intraspecific competition are stronger than the effects of interspecific competition (Tilman 1982; Grover 1997; Chesson 2000; Cross and Benke 2002). Our results suggested that the frequency of interspecific interactions is significantly less than that of intraspecific interactions (Figs. 4 and 5). The observed predominant negative intraspecific interaction (the probability is approximately $100 \%$ ) for the nine abundant species indicates that there should be less overlap in their ecological niche. Thus, density dependency must be a dominant force in maintaining species coexistences of functional groups like rodent species assemblages. It is notable that we found the interspecific interaction probability is around $10 \%$ for the 14 rodent species, suggesting niche overlap also exists between species but only among a small proportion of species. Strong interaction within the species and weak interaction among species often promote stability and coexistence of species in a community or ecosystem (May 1972; Tilman 1982; Rooney and McCann 2012).

Morris (2002) suggested that populations of small mammals may frequently reach low densities; therefore, positive density dependence may play a significant role in population persistence. This phenomenon is defined as the Allee effect which is common in population dynamics of rare species (Courchamp et al. 1999). It is interesting that we did not found any negative density dependence for the five rare species; instead, we found positive density dependence in two rare species (Lasiopodomys brandtii and Cardiocranius paradoxus). It is likely positive density-dependency is also important for the persistence of rare species in rodent communities. Besides this, we also found three non-monotonic interactions from abundant species on rare species, and one such interaction from a less abundant species to an abundant species. The non-monotonic interactions may be caused by spatial heterogeneity in species interactions but this also needs further investigation.

In summary, our study indicates that species assemblages in both space and time dimensions were determined by many factors including density dependency, species interaction, environmental variables and taxonomic relations. Our results revealed that resources partitioning through intra- and interspecific 
competition and environmental filtering by vegetation and climate played significant roles in shaping the community structure and dynamics of small mammals in arid grassland ecosystems. However, stochastic process or sampling errors may also contribute to the unexplained variances of species assemblages, and these factors require further investigation.

Acknowledgments We thank the Inner Mongolia Center for Endemic Diseases Control and Research for providing data of rodent abundance, the Environmental \& Ecological Science Data Center for West China, National Natural Science Foundation of China and the Chinese Ecosystem Research Network (CERN) for providing data of NDVI, precipitation, temperature and vegetation type. This research is co-supported by the State Basic Research Program of Ministry of Science and Technology (2007CB109100), the Foundation for the Author of National Excellent Doctoral Dissertation of P.R. China (FANEDD201069) and the New Century Excellent Talent Plan of the Ministry of Education of China (NCET-10-0310).

\section{References}

Austin MP (1985) Continuum concept, ordination methods, and niche theory. Ann Rev Ecol Syst 116:39-61

Berryman A, Turchin P (2001) Identifying the density-dependent structure underlying ecological time series. Oikos 92:265-270

Brown JS (1989) Desert rodent community structure: a test of four mechanisms of coexistence. Ecol Monogr 59:1-20

Cavender-Bares J, Keen A, Miles B (2006) Phylogenetic structure of floridian plant communities depends on taxonomic and spatial scale. Ecology 87(sp7):S109-S122

Chase JM, Leibold MA (2003) Ecological niches. University of Chicago Press, Chicago

Chen C (2000) Generalized additive mixed models. Communicaitons in statistics-theory and method, vol 29., pp 5-6

Chesson P (2000) Mechanism of maintenance of species diversity. Ann Rev Ecol Syst 31:343-366

Clarke KR, Ainsworth M (1993) A method of linking multivariate community structure to environmental variables. Mar Ecol 92:205

Cooper GJ (2003) The science of the struggle for existence. Cambridge University Press, Cambridge

Cooper N, Rodríguez J, Purvis A (2008) A common tendency for phylogenetic overdispersion in mammalian assemblages. Proc R Soc B 275:2031-2037

Courchamp F, Clutton-Brock T, Grenfell B (1999) Inverse density dependence and the Allee effect. Trend Ecol 14:405-410

Cox DR, Gudmundsson G, Lindgren G, Bondesson L, Harsaae E, Laake P, Juselius K, Lauritzen SL (1981) Statistical analysis of time series: some recent developments. Scand J Stat 8:93-115

Crawley MJ (2007) The R book. Wiley, Chichester
Cross WF, Benke AC (2002) Intra- and interspecific competition among coexisting lotic snails. Oikos 96(2):251-264

Cushman HJ, Whitham TG (1989) Conditional mutualism in a membracidant association: temporal, age-specific, and density-dependent effects. Ecology 70:1040-1047

Darwin C (1859) On the origin of species by means of natural selection or the preservation of favoured races in the struggle for life. John Murray, London

Edwards KF, Litchman E, Klausmeier CA (2013) Functional traits explain phytoplankton community structure and seasonal dynamics in a marine ecosystem. Ecol Lett 16:56-63

Efron B, Tibshirani RJ (1993) An introduction to the bootstrap. Chapman and Hall, London

Grover JP (1997) Resource competition. Chapman and Hall, London

Hutchinson GE (1957) Concluding remarks. Cold Spring Harbor symposia on quantitative biology, vol 22. Cold Spring Harbor Laboratory Press, Cold Spring Harbor, pp 415-427

Hutchinson GE (1959) Homage to Santa Rosalia or why are there so many kinds of animals? Am Nat 93:145-159

Incorporation S (2006) SPSS 13.0 for the Windows. SPSS Inc., Chicago

Jiang G, Zhao T, Liu J, Xu L, Yu G, He H, Krebs CJ, Zhang Z (2011) Effects of ENSO-linked climate and vegetation on population dynamics of sympatric rodent species in semiarid grasslands of Inner Mongolia, China. Can J Zool 89:678-691

Jiang G, Liu J, Xu L, Yu G, He H, Zhang Z (2013) Climate warming increases biodiversity of small rodents by favoring rare or less abundant species in grassland ecosystem. Integr Zool 8:162-174

Keddy P, Weiher E (1999) Introduction: The scope and goals of research on assembly rules. In: Weiher E, Keddy P (eds) Ecological assembly rules: perspectives, advances, retreats. Cambridge University Press, Cambridge

Kneitel JM, Chase JM (2004) Trade-offs in community ecology: linking spatial scales and species coexistence. Ecol Lett 7:69-80

Kotler BP, Brown JS (1988) Environmental hetergeneity and the coexistence of desert rodents. Ann Rev Ecol Syst 19:281-307

Lande R, Engen S, Saether BE (2003) Stochastic population dynamics in ecology and conservation. Oxford University Press, Oxford

León WA, Fraschina J, Guidobono JS, Busch M (2013) Habitat use and demography of Mus musculus in a rural landscape of Argentina. Integr Zool Sl:18-29

Lima M, Berryman A, Stenseth CN (2006) Feedback structures of northern small rodent populations. Oikos 112:555-564

Litchman E, Klausmeier CA (2008) Trait-based community ecology of phytoplankton. Ann Rev Ecol Syst 39:615-639

Losos JB (1996) Phylogenetic perspectives on community ecology. Ecology 77:1344-1354

Losos JB, Leal M, Glor REM, de Queiroz K, Hertz PE, Schettino LR, Lara AC, Jackman TR, Larson A (2003) Niche lability in the evolution of Caribbean lizard community. Nature 424:542-545

Ma W, Yang Y, He J, Zen H, Fang J (2008) Relationship between biological mass and environmental factors in Inner Mongolia of China. Sci in China (C) 38:84-92 
May RM (1972) Will a large complex system be stable? Nature 238:413-414

McGill BJ, Enquist BJ, Weiher E, Westoby M (2006) Rebuilding community ecology from functional traits. Trend Ecol 21:178-185

McPeek MA, Brown JM (2000) Building a regional species pool: diversification of the Enallagma damselflies in eastern North America. Ecology 81:904-920

Morris DW (2002) Measuring the Allee effect: positive density dependence in small mammals. Ecology 83:14-20

Mutshinda CM, O'Hara RB, Woiwod IP (2008) Species abundance dynamics under neutral assumptions: a Bayesian approach to the controversy. Funct Ecol 22:340-347

R Development Core Team (2013) R: a language and environment for statistical computing. R Foundation for Statistical Computing, Vienna, Austria. ISBN 3-900051-07-0. http:// www.R-project.org/

Ramsey F, Schafer D (2002) The statistical sleuth: a course in methods of data analysis. Duxbury Press, PacificGrove

Rangel TF, Diniz-Filho JAF, Bini LM (2010) SAM: a comprehensive application for spatial analysis in macroecology. Ecography 33:46-50

Rooney N, Mccann KS (2012) Integrating food web diversity, structure and stability. Trend Ecol 27:40-46

Saitoh T, Stenseth CN, Bjornstad ON (1997) Density dependence in fluctuating grey-sided vole populations. J Anim Ecol 66:14-24

Sasaki T, Lauenroth WK (2011) Dominant species, rather than diversity, regulates temporal stability of plant communities. Oecologia 166:761-768

Shenbrot GI, Rogovm KA, Surov AV (1991) Comparative analysis of spatial organization of desert lizard communities in Middle Asia and Mexico. Oikos 61:157-168

Silvertown J, Dodd M, Gowing D (2001) Phylogeny and the niche structure of meadow plant communities. J Ecol 89:428-435

Steward FM, Levin BR (1973) Partioning of resources and the outcome of interspecific competition: a model and some general considerations. Am Nat 107:171-198

Stige LC, Ottersen G, Brander K, Chan KS, Stenseth NC (2006) Cod and climate: effect of the North Atlantic Oscillation on recruitment in the North Atlantic. Mar Ecol 325:227-241
Tilman D (1982) Resource competition and community structure. Princeton University Press, Princeton, p 296

Travis JMJ, Brooker RW, Clark EJ, Dytham C (2006) The distribution of positive and negative species interactions across environmental gradients on a dual-lattice model. J Theory Biol 241:896-902

Turchin P (1990) Rarity of density dependence or population regulation with lags? Nature 344:660-663

Viljugrein H, Stenseth NC, Smith GW, Steinbakk GH (2005) Density dependence in North American ducks. Ecology 86:245-254

Wang G, Hobbs NT, Twombly S, Boone RB, Illius AW, Gordon IJ, Gross JE (2009) Density dependence in northern ungulates: interactions with predation and resources. Popul Ecol 51:123-132

Ward JH (1963) Hierarchical grouping to optimize an objective function. J Am Stat A 58:236-244

Webb CO, Peart DR (2000) Habitat associations of trees and seedlings in a Bornean rain forest. J Ecol 88(3):464-478

Webb CO, Ackerly DD, McPeek MA, Donoghue MJ (2002) Phylogenies and community ecology. Ann Rev Ecol Syst 33:475-505

Wilson WG, Lundberg P (2006) Non-neutral dynamics: empirical predictions for ecosystem function and diversity from linearized consumer-resource interactions. Oikos 114:71-83

Wilson DE, Reeder DM (2005) Mammal species of the world: a taxonomic and geographic reference. Johns Hopkins University Press, Baltimore

Winston MR (1995) Cooccurrence of morphologically similar species of stream fishes. Am Nat 145:527-545

Wood SN (2006) Generalized additive models: an introduction with R. CRC Press, Boca Raton

Yan C, Xu L, Xu T, Cao X, Wang F, Wang S, Hao S, Yang H, Zhang Z (2012) Agricultural irrigation mediates climatic effects and density dependence in population dynamics of Chinese striped hamster in North China Plain. J Anim Ecol 82:1365-2656

Zhang Z (2013) Biological consequences of global change: past and future. Integr Zool 8:123 